\title{
The Capability to Make Ice from Sunlight Utilizing a New Absorption Unit of Nano-Coated Ammonia/Calcium Chloride
}

\author{
Mohammed Awwad Ali Al-Dabbas \\ Mechanical Engineering Department, Mutah University, Karak 61710, Jordan \\ Corresponding Author Email: madabbas@mutah.edu.jo
}

https://doi.org/10.18280/ijht.390421

Received: 16 May 2021

Accepted: 20 July 2021

\section{Keywords:}

Ice producer, Ammonia/calcium chloride, absorption, nanofluid particle -materials, solar, domestic systems, and paint mixture

\begin{abstract}
In southern Jordan, the ice machine was designed, produced, operated, and fully examined at Mutah University, a unique Nano-coated ammonium/calcium chloride absorption sun unit. Analytical and experimental assessments on the use of ammonia/calcium chloride absorption unit ice produced. The new study has decreased energy emission by the Nano ice-making company while enhancing Nano's ice machine's nuclear power compared to standard solar chiller absorption that is not used in the current research. Our case was the world's first research to examine the effect of a nanoparticle combination of paint on an absorption cooling system used to make ice by the sunlight. The result of the test was quite encouraging. The combination of paint and nanofluid particle materials has boosted the accessibility to sun-based cooling processes and their capability to make ice of absorption. In addition, 0.6 was found to be a pretty good COP for the ammonia/calcium chloride solar system of absorption.
\end{abstract}

\section{INTRODUCTION [1-10]}

The Karak area in South Jordan has enormous solar power that makes it suitable for initiatives for solar-oriented energy. The sun-based cooling method is mainly powered by the condenser, generator, capacity unit, and evaporator. This generator collects the surrounding sunrays energy and turns solar energy into valuable power, for instance, mechanical and electrical. Due to the nonuniformity of sunlight radiation energy, especially at night, an off-grid storing unit must be available [1-5].

In different aspects of the global community, there is a growing need for refrigeration. Solar energy generates electricity and chiller Innovative solution for kits [1-9].

Cooling regulated by solar energy is a specific system that minimizes the impact on the environment.

Solar cooling is a reasonably advanced technique nowadays. Many significant PV application projects have been performed before in Jordan. However, Jordan has been embedded with an unusual duty on refrigeration. The major obstacle for largescale use in Jordan is the lack of practical expertise and availability of this system [7].

Different exploratory techniques have found an ecologically friendly cooling system such as solar power. However, no previous artistry application has shown sunlight-based cooling methods that allow such systems to be highly warmly absorbed and of low thermal reflectivity.

This study finds paints that improve the availability and capability of cooling frameworks for the sun, and more specifically, those that make the most of the improved absorption effect for purposes of cooling.

Two controlled sun-based adsorption \& absorption refrigerators, built and run without electrical power, will lessen dependency on power in Mutah university environment.

The decline in traditional energy sources and the increase in environmental contamination will make increasing use of the solar cooling system. For example, in food preserving, facility air-conditioning, refrigerators, freezers, ice production, cooler, solar cooling, etc., can be employed [10]

\subsection{Solar refrigeration's advantages [1-10]}

Solar power is the major energy source used to operate the solar cooler. This saves considerable electrical capacity and reduces the pollutants that ordinary electricity plants would have contributed to them.

What are the key challenges?

It needs larger collectors to produce enough energy from the solar system. Thus, the collector needs more area, which is another essential difficulty for using the system for sunlight refrigeration. The initial cost is also essential to establish such a system.

\subsection{Solar refrigeration's disadvantages [1-10]}

The solutions of solar refrigeration also have significant drawbacks. Since sunlight radiation energy is not accessible all day long, electrical power is not generated evenly. It depends again on the radiation strength of the beam.

The average solar radiant flow is never more than $1 \mathrm{kWh} / \mathrm{m}^{2}$, while the maximum radiation flux is roughly $6 \mathrm{kWh} / \mathrm{m}^{2}$ in the hottest locations on earth.

In terms of technology use, these are low rates. Those cooling methods can also be employed where they do not provide issues. However, it needs larger collectors to produce enough energy from the solar system. Thus, the collector needs more area, which is another essential difficulty for using the sunlight cooling methods. The initial cost is also significant to establish such a system. 


\section{DIFFICULTIES [7-11]}

As a result of the day/night cycle and the Earth's orbital movement around the sun, the available accessibility of sunlight radiation changes every day. Furthermore, due to local meteorological circumstances, fluctuation takes place at a particular location. Therefore, during periods when the sun shines, energy received must be conserved for use when it is not obtainable. The necessity for storage substantially increases the system's costs. The main problem in using sunlight thermal energy as an alternate source is thus to resolve these problems. We must create cheaper collecting and storage processes to decrease the high initial expenditure in many systems.

\subsection{Adsorption refrigeration unit [7-11]}

Several typical adsorbents (solid)/adsorbate(gas) pairs are utilized within the refrigeration unit of the adsorption. Adsorbents such as zeolite, silica gel, and active carbon adsorbate(gasses) are most commonly employed in solar adsorbed adsorbents, for example, methanol or ammonium water. Thus, a chemical process termed an adsorption cycle occurs between the invading gas and the solid in the dynamo unit.

Figure 1 depicts a cold chamber, a vacuum pump, a flat solar receiver unit, an evaporator, and a condenser, which are all parts of a nano adsorption refrigeration system developed at Mutah University, with some of its pieces covered with dull carbon black paint containing selective nano elements. And the pair of adsorbent/adsorbate will be inserted into the solar plate collector.

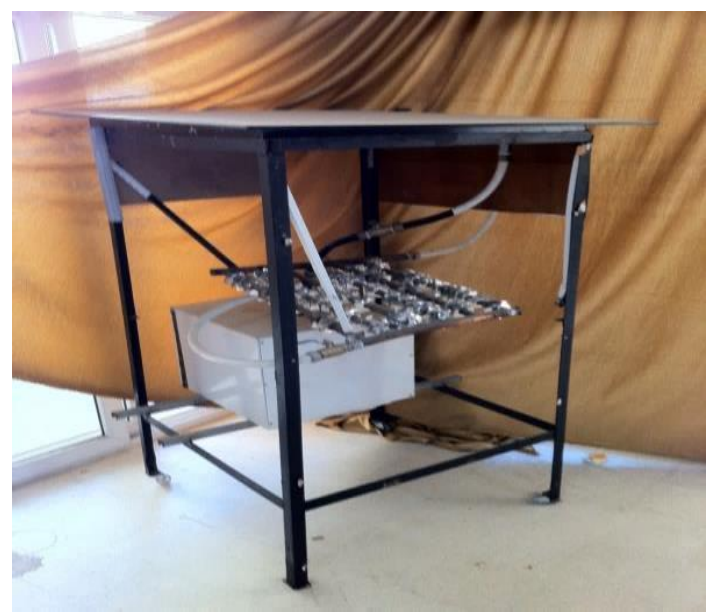

Figure 1. NANO Adsorption sun based cooling generator unit [7]

1) The sunlight receiver includes a copper tube that serves as the central part of the adsorption unit and is covered with a dull carbon black paint containing nano components. Carbon, Molybdenum, and Chromium are among the nanomaterials mentioned.

2) In selecting the evaporator size, the variables about the needed cyclical adsorbate weight, the ambient exchange area, in addition free area to be left in that evaporator must be considered.

3) The adsorption impact is generated by an adsorbent/adsorbate twosome positioned within the mentioned solar receiver, wherein the adsorbent contains activated silica gel, carbon, or zeolite, and the mentioned adsorbate includes one or more of the following: methanol, water, or ammonia.

4) The cold chamber might be a cabinet or a space for storing and preserving cold food or other items.

5) In the South of Jordan in Mutah University, a factory is internally constructed, run, and extensively monitored utilizing methanol and activated carbon as adsorbents/adsorbents. The cold chamber's temperature was recorded at 8 Celsius. Also, after applying that dull carbon black paint with that Nano, the thermal emissivity was lowered to 0,7 for the traditional collector. Also, the conventional collector's thermal efficiency has risen by 11 percent in our study system [7].

\subsection{Absorption cooling unit [10-23]}

The absorption cycle begins with the collection of solar radiation that is transformed into thermal energy. The thermal heat will increase the salt ammonia mixture temperature in the generator with the rise in ammonia amount. The liquid ammonia will be stored in the reservoir after condensing the vapor ammonia via the condensing coil.

Figure 2 shows a sunlight cooling system with absorptions, which has a water reservoir, parabolic solar generator, cold chamber, and condenser with certain sections coated with dull carbon black paint and possessing selected nanomaterials. The parabolic sunlight receiver contains a copper tube that is utilized to incorporate the absorption/absorption pair.

1) The parabolic sunlight radiation receiver captures sunlight and turns it into thermal heat energy, which warms up thermal energy.

2) A parabolic sunlight radiation receiver is coupled with this condenser, where it is connected via a water reservoir to that cold chamber. The tank mentioned above releases the heat from the vapor absorbed.

3) The parabolic generator includes many distrusted fins, where the fins enhance the heat transmission between an absorbing/absorbing pair.

4) Furthermore, the illustrative tube has coated a dull carbon black paint, while the collector tube comprises nanomaterials. These nanomaterials contain carbon, chromium, carbon, and molybdenum. The condenser is a tube made of copper that permits the absorbate vapors from that same parabolic collector to condense.

5) The absorption impact is performed by utilizing an absorbent pair within the tube, as mentioned earlier, in which the ammonia is included in this absorbent and calcium chloride is contained in that absorbate.

6) The cold chamber might be a cabinet or a space for storing and preserving cold food or other items.

The typical cycle sequence. (see Figure 2).

The phenomena of absorption happened when ammonia and calcium chloride are mixed inside the generator. The Absorption Chiller concept is the same as the Air Chiller vapor Compression. As the sun's intensity light reaches the parabolic solar receiver unit, solar radiation is collected by the absorber plate and transformed to heat energy. This thermal radiation will raise the ammonia temperature and calcium chloride combination in the generator, helping the coolant release from the absorbing substance. Thus, the condenser's heat exchanger will transform ammonia from vapor to liquid phase, which is kept in the cold storage cabinet. 

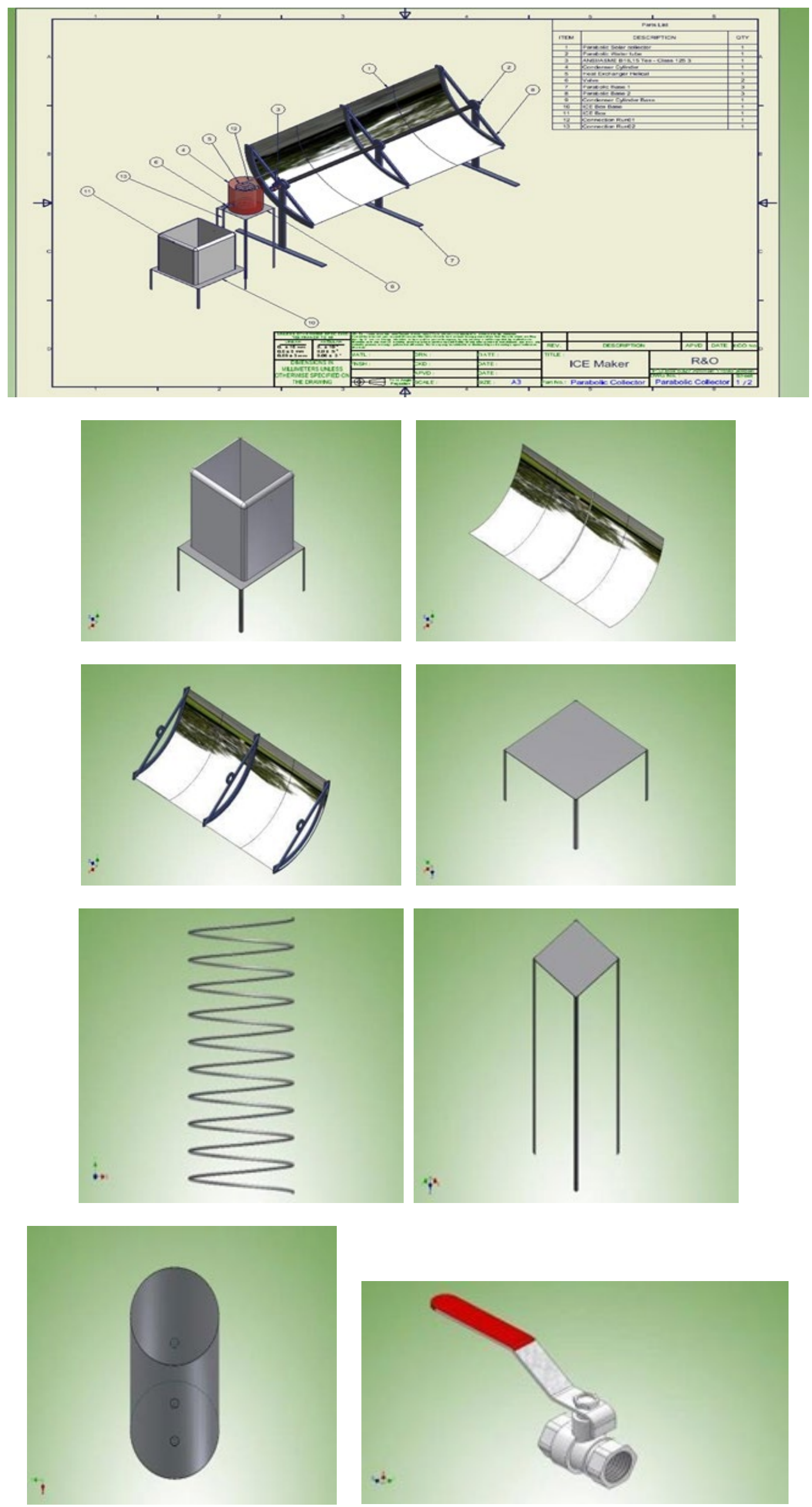

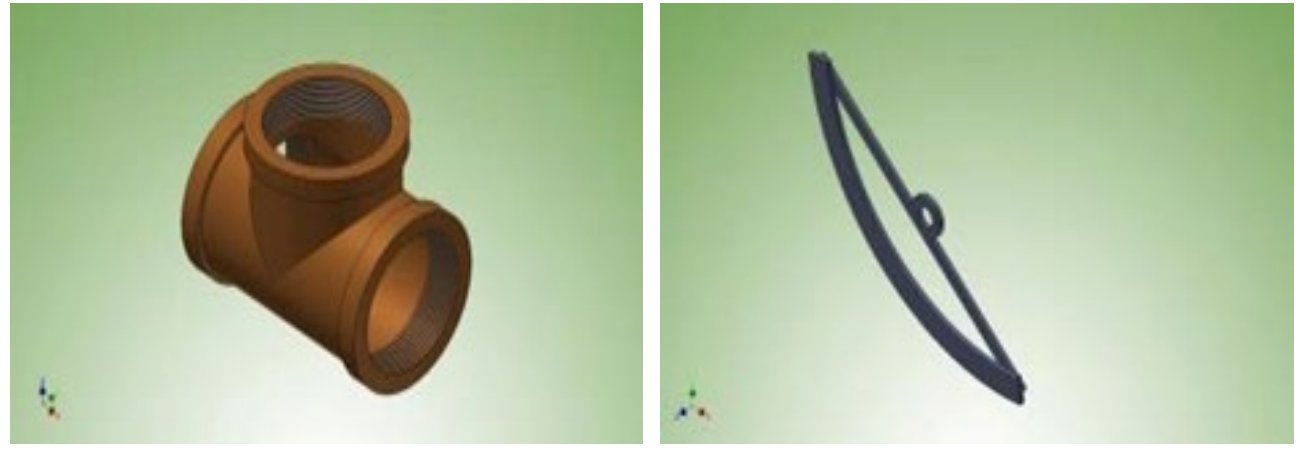

Figure 2. Nano absorption refrigeration cooling cycle and its segment components

\subsubsection{Ice maker components [24-33]}

Figure 3 shows a solar-powered ice machine part before assembly for ammonia/calcium chloride absorption.

\section{(1) Parabolic Solar Collector}

The solar cycle process begins by impacting the absorber plate of the Parabola solar receiver with the surrounding solar power. By concentrating the sunlight on the absorber plate, the Parabolic solar collector's mirrored surface speeds up the ammonia heating time and calcium chloride mixture. This will boost the temperature to its maximum value.

\section{(2) Condenser}

it's a helical tube condenser, was placed within the water reservoir to release the heat from the vapor so that the vapor could condense back to a liquid throughout the absorption; water cooling condenser.

\section{(3) Evaporator}
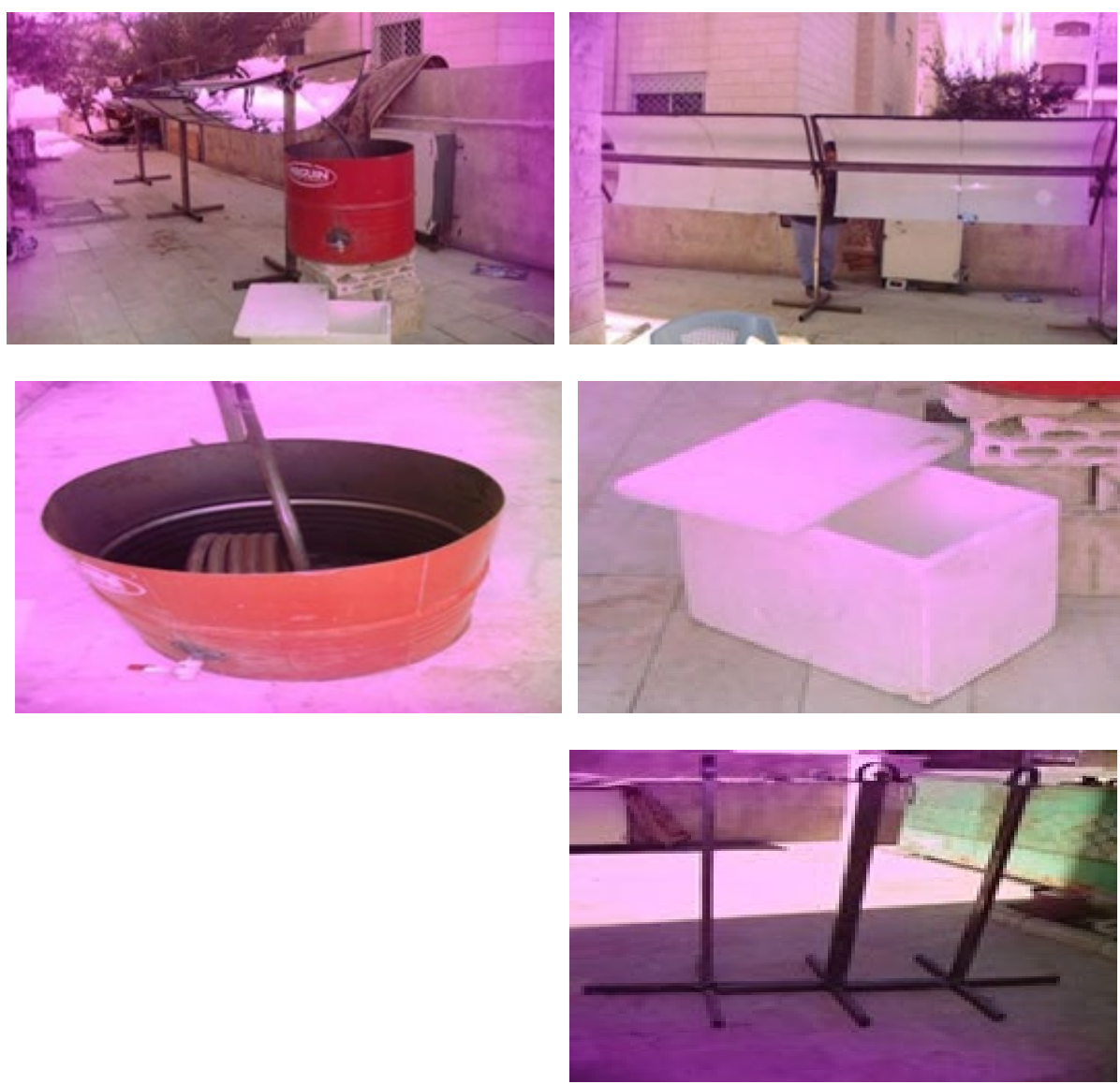

The coolant in the aluminum evaporator was utilized to collect the thermal heat of the outside environment and go it out. Therefore, the refrigerant can boil at extremely low pressures such that it absorbed heat from the heated chamber and moved to the absorber.

\section{(4) Parabolic base}

Steel parabolic bases are utilized to support the collector.

\section{(5) Generator pipe}

The generator pipe, which carries calcium-chloride ammonia, is employed in applications that need higher temperatures. The heat was used to convert ammonia to gas in solar-powered tubes.

\section{(6) Ice Box}

A cooling cabinet is an area where ammonia vapor evaporates and cooling occurs. These boxes are containers that contain water that has chilled to the point of becoming ice. 


\section{RESULT \& DISCUSSION}

The following are the reactions of calcium chloride with ammonia:

$$
\mathrm{CaCl} 2+2 \mathrm{NH} 3 \mathrm{CaCl} 2.2 \mathrm{NH} 3 \pm \mathrm{Q} 1
$$

$$
\begin{aligned}
& \mathrm{CaCl} 2.2 \mathrm{NH} 3+2 \mathrm{NH} 3 \mathrm{CaCl} 2.4 \mathrm{NH} 3 \pm \mathrm{Q} 2 \\
& \mathrm{CaCl} 2.4 \mathrm{NH} 3+4 \mathrm{NH} 3 \mathrm{CaCl} 2.8 \mathrm{NH} 3 \pm \mathrm{Q} 3
\end{aligned}
$$

The mass of the evaporator water is $5 \mathrm{~kg}$, while the absorption duration is 12 hours.

Instead of a mechanical vapor compressor, the absorber, solution pump, and generator work together to compress the refrigerant vapor in an absorption cycle chiller.

The pump pushed the generator's weak adsorbent.

At high temperatures, the generator receives heat. Also, the absorber refuses low heat.

The current condenser coolant fluid temperature is equal to the actual absorber coolant fluid temperature. The condenser will use vapor coolant, which was condensed [8].

The collector was oriented at east-west and faced the north. Condenser inlet, condenser water, pipe, condenser outlet, and evaporator have been monitored and reported with a thermocouple and electronic monitor every hour, as follows in Figures 4-8 $[8,9]$.

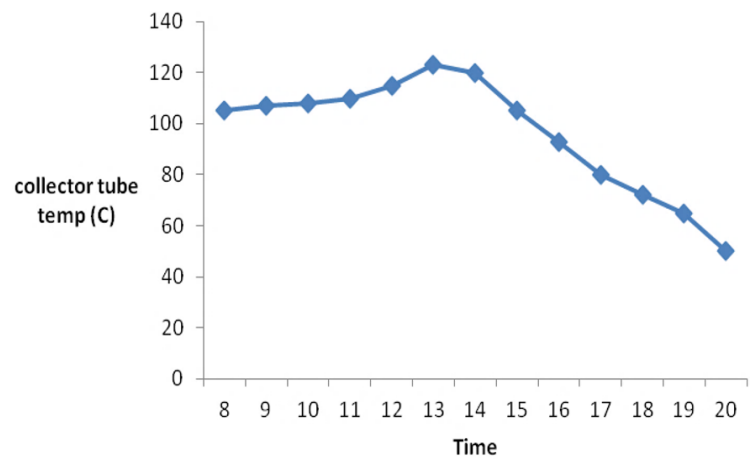

Figure 4. Collector temperature

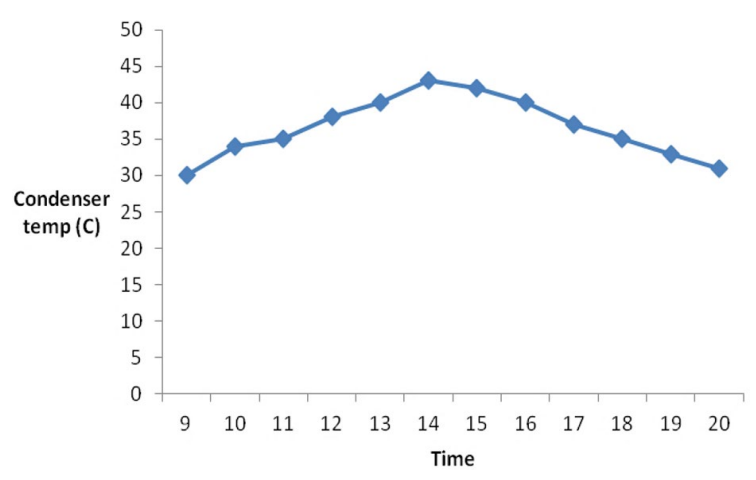

Figure 5. Condenser temperature

\section{Design parameter}

\begin{tabular}{cc}
\hline Solar brilliance & $1000 \mathrm{w} / \mathrm{m}^{2}$ \\
\hline Ambient warmth & $30^{\circ} \mathrm{C}$ \\
curtail warmth & $40^{\circ} \mathrm{C}$ \\
Evaporating warmth & $-10^{\circ} \mathrm{C}$ \\
Collector/generator warmth & $100^{\circ} \mathrm{C}$ \\
Final ice warmth & $-5^{\circ} \mathrm{C}$ \\
bearing age & $6 \mathrm{hrs}$ \\
\hline
\end{tabular}

The vaporizer water mass is $5 \mathrm{~kg}$, while the Absorption period is 12 hours,

$$
\begin{aligned}
& ==0.0001157 \mathrm{~kg} / \mathrm{s} \\
& ==0.0001157 \times 4.19 \times(130-80)=0.02423 \mathrm{kw} \\
& =0.0001157 \times 4.19 \times(92-80)=0.005817 \mathrm{kw} \\
& ==0.001157 \times 4.19 \times(130-92)=0.01842 \mathrm{kw} \\
& \text { Coefficients of performance: }- \text { Cop }==0.31
\end{aligned}
$$

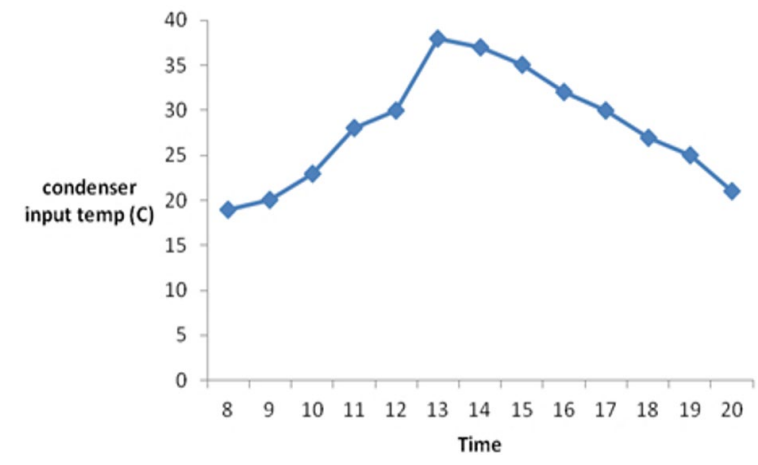

Figure 6. Condenser water temperature

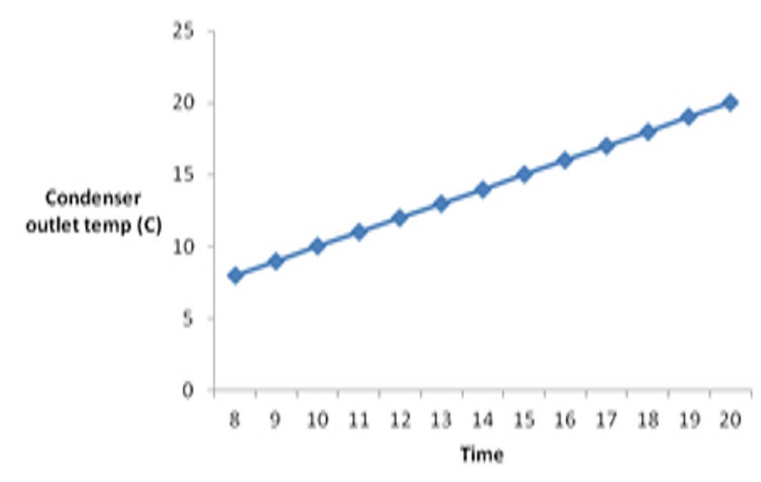

Figure 7. Condenser out temperature

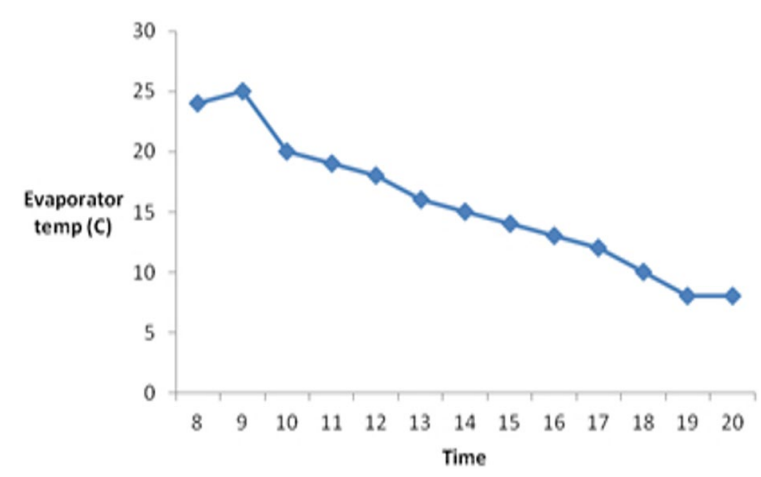

Figure 8. Evaporator temperature

\section{CONCLUSION}

Previous applications of study have not shown a coating for adsorption and absorption solar cooling technique capable of producing such systems with high thermal absorption and low thermal reflection. In this project, An Ammonia/calcium chloride absorption ice machine fed by sunlight was developed, built, operated, and extensively monitored and assessed in the south of Jordan at Mu'tah University.

This ice maker can be implemented to preserve meat, dairy goods, vaccines, household items, or as energy-saving and ecologically beneficial appliances.

The research demonstrates the viability of the innovative 
Nano painted Ammonia/calcium chloride absorption ice maker unit.

\section{ACKNOWLEDGMENT}

This exploration research was designed, built, operated, and fully monitored and evaluated in southern Jordan in Mu'tah University. We are enormously greatly thanking ABDEL_HAMID SHOUMAN ESTABLISHMENT for their supply to our research until it becomes applicable.

\section{REFERENCES}

[1] Al Tarabsheh, A., Ababne, M.. Etier, I. (2010). Analysis of solar radiation in Jordan. Jordan Journal of Mechanical and Industrial Engineering, 4(6): 733-737.

[2] Girisha, N., Manikumar, K.C., Manjunath, H.N., Gowda, S.H., Kapilan, N. (2016). A study on effect of alternative refrigerant on the performance of a domestic refrigerator. Journal of Mechanical Engineering and Automation, $6(5 \mathrm{~A})$ :

138-141. https://doi.org/10.5923/c.jmea.201601.26

[3] Hussein, W.K.S. (2008). Solar energy refrigeration by liquid-solid adsorption technique (Doctoral dissertation). An-Najah National University Faculty of Graduate Studies. https://hdl.handle.net/20.500.11888/6780

[4] Abdulateef, J.M., Sopian, K., Alghoul, M.A., Sulaiman, M.Y. (2009). Review on solar-driven ejector refrigeration technologies. Renewable and Sustainable Energy Reviews, 13(6-7): 1338-1349. https://doi.org/10.1016/j.rser.2008.08.012

[5] World Health Organization. The module: The vaccine cold chain, IIP2015 Module2. https://www.who.int/immunization/documents/IIP2015 Module2.pdf.

[6] Al-Dabbas, M.A. (2012). The performance of the first Jordan Badia's solar powered refrigerator. Applied Solar Energy, $\quad 48(3)$ :

175-179. https://doi.org/10.3103/S0003701X12030036

[7] Al-Dabbas, M.A. (2013). The performance of Nano adsorption solar cooling generator unit. In 2013 1st International Conference \& Exhibition on the Applications of Information Technology to Renewable Energy Processes and Systems, pp. 55-59. https://doi.org/10.1109/IT-DREPS.2013.6588150

[8] Al-Dabbas, M.A. (2014). The performance of hybrid photovoltaic thermal (PV/T) solar collector. A Jordanian Case, Distributed Generation and Alternative Energy Journal, 30(2): 8-22. http://www.tandfonline.com/toc/ucgn21/current\#.UZSa urUp_Is.

[9] Al-Dabbas, M.A.A. (2013). The performance of the first pilot thermoacoustic refrigerator. Journal of Energy and Power Engineering, 7(11): 2106-2114. www.davidpublishing.com/DownLoad/?id=14842.

[10] Karno, A., Ajib, S. (2008). Thermodynamic analysis of an absorption refrigeration machine with new working fluid for solar applications. Heat and Mass Transfer, 45(1): 71-81. https://doi.org/10.1007/s00231-008-04082

[11] Venkatarathnam, G., Murthy, S.S. (2012). Refrigerants for vapour compression refrigeration systems.
Resonance,

17(2):

$139-162$

https://doi.org/10.1007/s12045-012-0015-x

[12] Gill, J., Singh, J. (2017). Performance analysis of vapor compression refrigeration system using an adaptive neuro-fuzzy inference system. International Journal of Refrigeration, 82: 436-446. https://doi.org/10.1016/j.ijrefrig.2017.06.019

[13] Soni, J., Gupta, R.C. (2013). Performance analysis of vapour compression refrigeration system with R404A, R407C and R410A. International Journal of Mechanical Engineering and Robotics Research, 2(1): 25-36.

[14] Honeywell, Storage, Handling and Use Guidelines for Solsticezd Refrigerant. Solstice zd-handling guidelines. http://www.refrigeration.europe.honeywell.com/70_refr igeration_control/EN5B-0024UK07\%20R0505.pdf

[15] Czarnecki, J.T. (1958). Performance of experimental solar water heaters in Australia. Solar Energy, 2(3-4): 26. https://doi.org/10.1016/0038-092X(58)90046-X

[16] Ghali, K., Othmani, M., Ghaddar, N. (2008). Energy consumption and feasibility study of a hybrid desiccant dehumidification air conditioning system in Beirut. International Journal of Green Energy, 5(5): 360-372. https://doi.org/10.1080/15435070802414280

[17] Rosiek, S., Batlles, F.J. (2009). Integration of the solar thermal energy in the construction: Analysis of the solarassisted air-conditioning system installed in CIESOL building. Renewable Energy, 34(6): 1423-1431. https://doi.org/10.1016/j.renene.2008.11.021

[18] Enteria, N., Yoshino, H., Mochida, A., Takaki, R., Satake, A., Yoshie, R. (2009). Construction and initial operation of the combined solar thermal and electric desiccant cooling system. Solar Energy, 83(8): 1300-1311. https://doi.org/10.1016/j.solener.2009.03.008

[19] Zhai, X.Q., Wang, R.Z., Wu, J.Y., Dai, Y.J., Ma, Q. (2008). Design and performance of a solar-powered airconditioning system in a green building. Applied Energy, 85(5):

https://doi.org/10.1016/j.apenergy.2007.07.016

[20] Stanciu, C., Stanciu, D., Gheorghian, A.T. (2017). Thermal analysis of a solar powered absorption cooling system with fully mixed thermal storage at startup. Energies, 10(1): 72. https://doi.org/10.3390/en10010072

[21] Cascetta, F., Cirillo, L., Della Corte, A., Nardini, S. (2017). Comparison between different solar cooling thermally driven system solutions for an office building in Mediterranean Area. International Journal of Heat and Technology, 35: 130-138. https://doi.org/10.18280/ijht.350118

[22] Sibley, H.W. (1985). Kirk-Othmer Encyclopedia of Chemical Technology. Refrigeration. John Wiley \& Sons. https://doi.org/10.1002/pi.4980180615

[23] Hassan, H.Z. (2013). A solar powered adsorption freezer: A case study for Egypt's climate. International Journal of Energy Engineering, 3(1): 21-29.

[24] Lemmini, F., Errougani, A. (2005). Building and experimentation of a solar powered adsorption refrigerator. Renewable Energy, 30(13): 1989-2003. https://doi.org/10.1016/j.renene.2005.03.003

[25] Rezk, A.R., Al-Dadah, R.K. (2012). Physical and operating conditions effects on silica gel/water adsorption chiller performance. Applied Energy, 89(1): 142-149.

https://doi.org/10.1016/j.apenergy.2010.11.021

[26] Eicker, U. (2006). Solar Technologies for Buildings. 
John Wiley \& $\quad$ Sons. https://doi.org/10.1002/0470868341.ch8

[27] Louajari, M., Mimet, A., Ouammi, A. (2011). Study of the effect of finned tube adsorber on the performance of solar driven adsorption cooling machine using activated carbon-ammonia pair. Applied Energy, 88(3): 690-698. https://doi.org/10.1016/j.apenergy.2010.08.032

[28] Metcalf, S.J., Tamainot-Telto, Z., Critoph, R.E. (2011). Application of a compact sorption generator to solar refrigeration: Case study of Dakar (Senegal). Applied Thermal Engineering, 31(14-15): 2197-2204. https://doi.org/10.1016/j.applthermaleng.2010.11.001

[29] Karamanis, D., Vardoulakis, E. (2012). Application of zeolitic materials prepared from fly ash to water vapor adsorption for solar cooling. Applied Energy, 97: 334339. https://doi.org/10.1016/j.apenergy.2011.12.078

[30] Ghafoor, A., Munir, A. (2015). Worldwide overview of solar thermal cooling technologies. Renewable and
Sustainable Energy Reviews, 43: 763-774. https://doi.org/10.1016/j.rser.2014.11.073

[31] Anyanwu, E.E., Ezekwe, C.I. (2003). Design, construction and test run of a solid adsorption solar refrigerator using activated carbon/methanol, as adsorbent/adsorbate pair. Energy Conversion and Management, 44(18): 2879-2892. https://doi.org/10.1016/S0196-8904(03)00072-4

[32] Loh, W.S., El-Sharkawy, I.I., Ng, K.C., Saha, B.B. (2009). Adsorption cooling cycles for alternative adsorbent/adsorbate pairs working at partial vacuum and pressurized conditions. Applied Thermal Engineering, 29(4):

793-798.

https://doi.org/10.1016/j.applthermaleng.2008.04.014

[33] Wang, L.W., Wang, R.Z., Oliveira, R.G. (2009). A review on adsorption working pairs for refrigeration. Renewable and Sustainable Energy Reviews, 13(3): 518534. https://doi.org/10.1016/j.rser.2007.12.002 